\title{
Effects of glucose, propionic acid, and nonessential amino acids on glucose metabolism and milk yield in Holstein dairy cows
}

\author{
S. Lemosquet, ${ }^{*} \dagger^{1}$ E. Delamaire, ${ }^{*} \dagger$ H. Lapierre, $\neq$ J. W. Blum, $\S$ and J. L. Peyraud ${ }^{*} \dagger$ \\ *INRA, UMR1080, Dairy Production, F-35590 Saint-Gilles, France \\ †Agrocampus Ouest, UMR1080, Dairy Production, F-35000 Rennes, France \\ fDairy and Swine Research and Development Centre, Agriculture and Agri-Food Canada, STN Lennoxville, Sherbrooke, QC, Canada, J1M 1Z3 \\ §Veterinary Physiology, Vetsuisse Faculty, University of Bern, CH-3012 Bern, Switzerland
}

\section{ABSTRACT}

Whole-body glucose rate of appearance ( $\mathrm{Ra}$ ) responses and milk lactose secretion were compared in dairy cows receiving duodenal infusions of glucose (Glc), a mixture of 5 nonessential amino acids (NEAAm), or ruminal infusions of propionic acid (C3). Four mid-lactation Holstein cows, fitted with both duodenum and rumen cannulas, were used in a $4 \times 4$ Latin square design with 14 -d periods. Cows were fed a grass silage-based diet (Ctrl) that provided $88 \%$ of net energy of lactation and $122 \%$ of protein requirements. Concentrate was formulated with wheat $(21.5 \%)$ and barley $(20 \%)$ containing some starch. Isoenergetic infusions $(5.15 \mathrm{Mcal} / \mathrm{d}$ of digestible energy) of Glc into the duodenum $(7.7 \mathrm{~mol} / \mathrm{d})$, C3 into the rumen $(14.1 \mathrm{~mol} / \mathrm{d})$, or NEAAm into the duodenum (in mol/d; Ala: 1.60; Asp: 0.60; Glu: 5.94; Gly: 1.22; Ser: 2.45) were given as a supplement to the Ctrl diet. During each period on d $13,\left[6,6-{ }^{2} \mathrm{H}_{2}\right]$ glucose was infused into one jugular vein and blood samples were taken from the other jugular vein to measure glucose enrichment and determine Ra. Dry matter intake decreased slightly with the infusions $(6 \%)$, but did not differ among them. Whole body glucose Ra averaged $502,745,600$, and $576 \mathrm{mmol} / \mathrm{h}$ for Ctrl, Glc, C3, and NEAAm, respectively. It increased with the increase in energy supply (Ctrl vs. infusions) and differed according to the nutrients infused. The Ra response was higher with Glc and C3 than with NEAAm and higher with Glc than with C3. Plasma concentrations of insulin were not affected, but insulin-like growth factor 1 increased with infusions. Plasma glucagon increased with NEAAm, which could favor the increased Ra. Overall, milk lactose yield $(137,141,142$, and $130 \mathrm{mmol} / \mathrm{h}$ for Ctrl, Glc, C3, and NEAAm, respectively) was not modified by the infusions, but was lower with NEAAm compared with Glc and C3. Changes in lactose yield

Received August 6, 2008.

Accepted February 23, 2009.

${ }^{1}$ Corresponding author: Sophie.Lemosquet@rennes.inra.fr did not parallel the increase in Ra, and therefore the ratio of lactose yield to Ra decreased with the infusions and was lower in Glc compared with C3, suggesting a shift of glucose utilization away from lactose synthesis toward other pathways, including mammary metabolism. Intestinal Glc was the most efficient nutrient in terms of increasing glucose Ra; however, there was no direct link between the increases in whole body glucose Ra observed with the 3 types of nutrients and milk lactose yield.

Key words: dairy cow, glucose metabolism, propionic acid, amino acid

\section{INTRODUCTION}

An increase in digestible energy intake has been shown to increase posthepatic glucose supply (review by Wieghart et al., 1986). In ruminants, glucose net availability is mainly dependent on gluconeogenesis, and the main glucogenic nutrients are propionic acid (C3), glucogenic AA, and lactate (Danfaer, 1994). In the lactating dairy cow, intestinal starch digestion could also account for a significant portion of whole-body glucose availability because the capacity for starch digestion in the small intestine seems to be significant (maximum disappearance $3.4 \mathrm{~kg} / \mathrm{d}$ ), although the recovery of postruminally infused purified starch as glucose in the portal vein only ranged from 19 to $46 \%$ of the infusion rate (Reynolds, 2006).

Meta-analyses and modeling approaches tried to estimate end products of digestion and to predict whole-body glucose availability in ruminants with the objective to improve current feeding systems based on energy value of feed (Bermingham et al., 2008). However, in lactating dairy cows, only a few experiments have studied the effects of individual macronutrients infused in the digestive tract on the whole-body glucose rate of appearance (Ra) or the splanchnic release of glucose, and even fewer experiments have compared the effects of 2 macronutrients (Clark et al., 1977; Lemosquet et al., 2004a). Direct supply of glucose (Glc) through 
postruminal infusions (Clark et al., 1977; Rigout et al., 2002; Lemosquet et al., 2004a) or starch (Reynolds, 2006) increases or tends to increase $\mathrm{Ra}$ or post-liver flow of glucose. However, C3 provided as infusions or in feed for ruminants does not cause a clear-cut increase in $\mathrm{Ra}$ or in hepatic glucose release (review by Kristensen, 2005). In dairy cows, rumen C3 infusion increased Ra to a lesser extent than did postruminal isoenergetic infusion of Glc (Lemosquet et al., 2004a). Also, postruminal infusions of casein were found to significantly or numerically increase $\mathrm{Ra}$ in lactating dairy cows (Clark et al., 1977; König et al., 1984). Two studies have compared postruminal Glc and casein infusions in lactating ruminants. Only numerical effects of treatments were observed on Ra in cows (Clark et al., 1977), whereas in goats Ra was increased only by casein (Ranawana and Kellaway, 1977).

In lactating dairy cows, mammary uptake of water and, consequently, milk yield greatly depends on mammary lactose synthesis through osmotic regulation. Because glucose is the main precursor for lactose synthesis, an increase in posthepatic glucose availability could be a potential regulator of milk yield. Indeed, Danfaer (1994) reported a linear relationship between whole body glucose flux rate and milk yield. In lactating cows receiving diets providing almost no intestinal starch (grass silage), an increase in Ra was suggested to be the key factor in increasing milk and lactose yields (Rigout et al., 2002, 2003). However, an isoenergetic comparison of the effect of C3 and Glc on Ra and milk yield (Lemosquet et al., 2004a) did not provide clear evidence of whether the increase in $\mathrm{Ra}$ was the key mechanism, because at the highest dose infused the Glc treatment increased Ra more than C3 did, whereas both nutrients only tended to increase milk yield. In addition, casein infusions increased milk yield but Glc infusions did not, although they had a similar effect on Ra (Clark et al., 1977). The effect of casein on Ra has generally been attributed to the supply of glucogenic AA, mainly nonessential AA (NEAA), but infusion of the NEAA fraction of casein did not increase milk yield (Kim et al., 2000).

Taken together, these findings raise the issue of the relationship between whole-body glucose availability and lactose yield, that is, whether lactose synthesis is driven by whole-body glucose availability or whole-body glucose availability is driven by lactose synthesis. The hypothesis of increased lactose synthesis in response to increased glucose Ra should be examined in a single experiment concomitantly studying the effect of several glucogenic nutrients. The aim of the experiment described herein was therefore to quantify the efficiency of isoenergetic infusions of Glc, C3, and NEAA in terms of increasing Ra and to analyze if lactose synthesis was driven by glucose Ra.

\section{MATERIALS AND METHODS}

\section{Cows, Experimental Design, and Treatments}

Four multiparous lactating Holstein cows fitted with a rumen cannula and a T-shaped duodenal cannula received 4 treatments according to a $4 \times 4$ Latin square design with 14-d periods. The complete experiment was conducted in accordance with National Legislation of Animal Care (certified by the French Ministry of Agriculture). Cows averaged $598 \pm 85 \mathrm{~kg}$ of BW, $77 \pm 17$ DIM, and produced $26 \pm 3 \mathrm{~kg} / \mathrm{d}$ of milk at the beginning of the study. In the first week of the experiment, the cows were fitted with 2 provisional silastic catheters (length, $30 \mathrm{~cm}$; i.d., $1.02 \mathrm{~mm}$; o.d., $1.6 \mathrm{~mm}$; PolyLabo 32608, Strasbourg, France) inserted into the 2 jugular veins for labeled glucose infusion and blood sampling. Catheter maintenance was as described by Lemosquet et al. (1997).

The cows were fed the same basal diet throughout the study. The diet was based on grass silage and concentrate was formulated to limit the amount of intestinal starch to by pass starch from wheat and barley contained in concentrate (Table 1). The same diet was fed to all the cows. It consisted of the following on a dry matter (DM) basis: $56.3 \%$ grass silage, $29.6 \%$ energetic concentrate (Table 1), 12.1\% formaldehyde-treated soybean meal and $2 \%$ mineral and vitamin premix. The intestinal starch was estimated to correspond to $15 \mathrm{~g} /$ $\mathrm{kg}$ DM of total diet (grass silage+concentrate) using the equations of Offner et al. (2003) and Offner and Sauvant (2004) and feed content of starch published in Sauvant et al. (2004). The 4 treatments (Table 2) consisted of continuous infusions of 1) water in the control (Ctrl); 2) Glc into the duodenum; 3) C3 into the rumen; and 4) a mixture of 5 NEAA (NEAAm; Ala, Asp, Glu, Gly, and Ser) into the duodenum. Infusions were formulated to provide the same amount $(5.15 \pm$ $0.05 \mathrm{Mcal} / \mathrm{d}$ ) of digestible energy (DE): the nutrients infused were supplemented on an iso-DE basis relative to a negative control (diet) to distinguish between the effect of DE supply and the effect of the type of nutrients. The NEAAm was composed of the 5 most oxidized AA described in ruminants (Black et al., 1990) administered in a proportion similar to that in casein, except for Asp because of its low solubility. Cows were individually fed a restricted diet providing $88 \%$ of their net energy requirements (INRA, 1989). Therefore, the combination of diet plus infusions provided approximately $100 \%$ of net energy requirements. The diet was 
Table 1. Chemical composition and nutritive value of feed ingredients

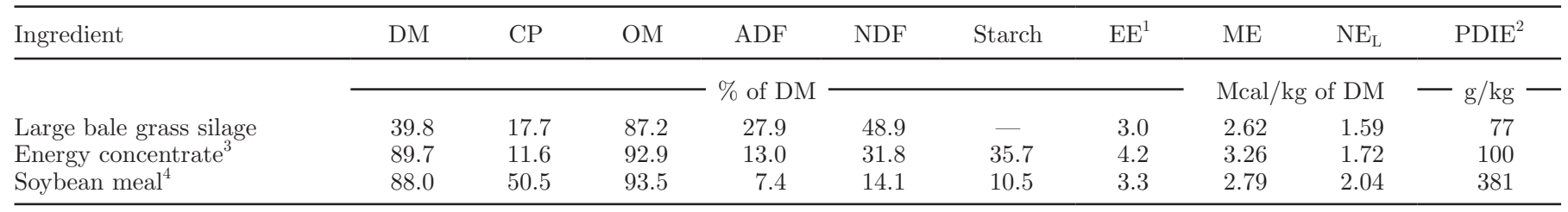

${ }^{1}$ Ether extract.

${ }^{2}$ Protein truly digested in the small intestine delimited by energy supply (INRA, 1989).

${ }^{3}$ Contained $20 \%$ barley, $21.5 \%$ wheat, $37 \%$ dried sugar beet pulp, $15 \%$ fine wheat bran, $2 \%$ soybean oil, $2 \%$ cane molasses, $0.5 \%$ calcium carbonate, $1 \%$ calcium bicarbonate, $1 \% \mathrm{NaCl}$ on $\mathrm{DM}$ basis.

${ }^{4}$ Soybean meal spray-treated with $1 \%$ formaldehyde.

formulated to provide $122 \%$ of protein requirements (INRA, 1989) expressed as protein digestible in the intestine (PDI) so as to avoid any limiting effect of protein supply on endogenous glucose production and on milk and protein yields.

\section{Milking, Feeding, and Infusions}

The cows were milked twice daily, at 0630 and 1730 h. Grass silage was fed 3 times per day $(25 \%$ at 0730 h, $25 \%$ at $1330 \mathrm{~h}, 50 \%$ at $1930 \mathrm{~h}$ ) and concentrate 8 times a day in equal portions (every $3 \mathrm{~h}$ from $0730 \mathrm{~h}$ onwards). Access to feed was limited to $1 \mathrm{~h}$ after each concentrate feeding. This pattern of feed distribution was adopted to maintain stable plasma concentrations of most blood metabolites (glucose, AA, acetate, BHBA, NEFA, urea) and hematocrit.

The first $2 \mathrm{~d}$ of each period included a transition for the infusions (the cows received $33 \%$ of the total subsequent infusion on $\mathrm{d} 1$, and $66 \%$ on $\mathrm{d} 2$ ). Solutions were infused continuously using peristaltic pumps. Details of infusions are given in Table 2. All the cows in all treatments received a similar volume of water (Table 2 ) in the rumen (about $48.3 \mathrm{~kg}$ ) and in the duodenum (about $20.3 \mathrm{~kg})$. Buffers $\left(\mathrm{NaHCO}_{3}\right.$ and $\left.\mathrm{KHCO}_{3}\right)$ were infused into the rumen to limit the ruminal $\mathrm{pH}$ decrease and avoid acidosis with C3 treatment (Table 2). The same solution was infused into the rumen during Ctrl and

Table 2. Continuous infusions of nutrients, water, and buffers into the rumen and the duodenum

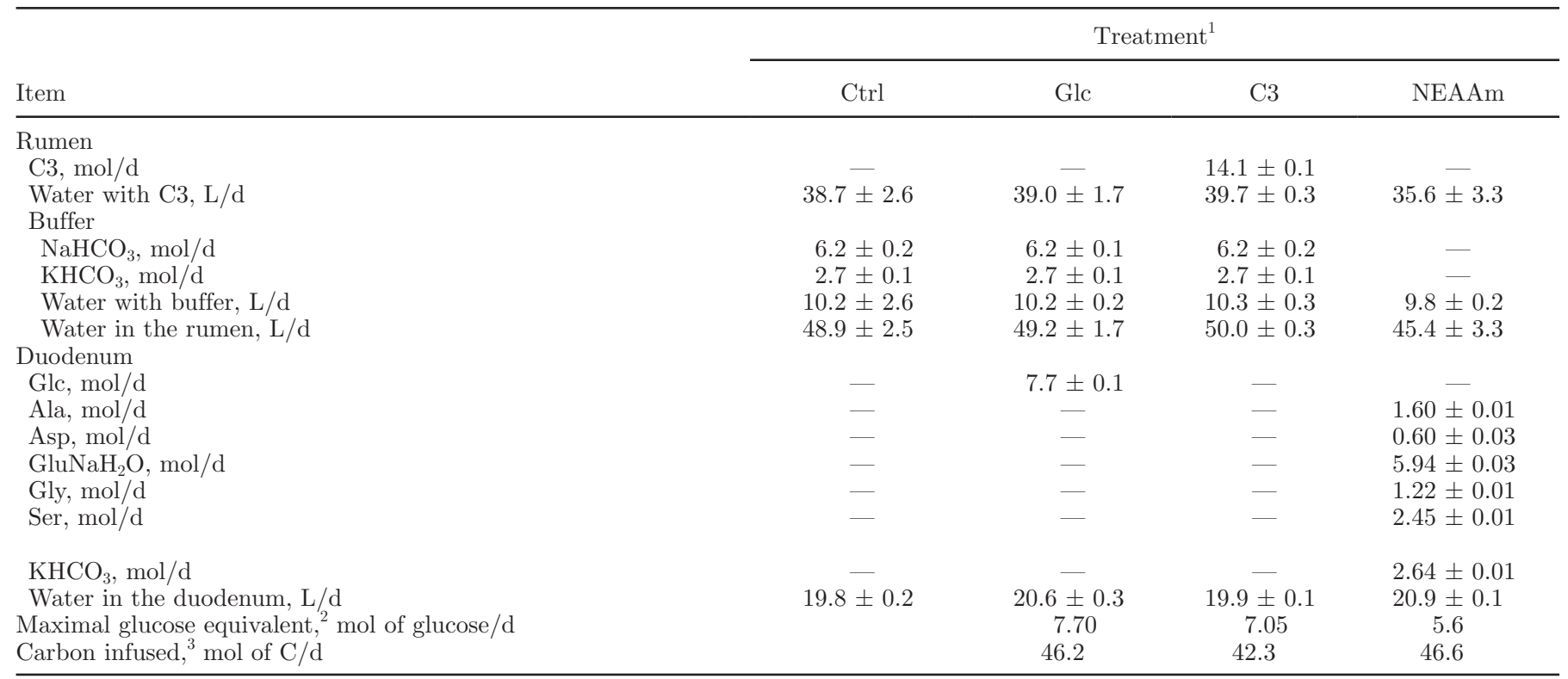

${ }^{1} \mathrm{Ctrl}=$ water as control; Glc $=$ monohydrated glucose (Merck-Clevenot Laboratories, Nogent sur Marne, France); C3 = propionic acid (Merck S.A., Chells, France); NEAAm $=$ a mixture of 5 nonessential amino acids (Dolder, Basel; Swiss). In NEAAm, the same amount $\mathrm{Na}^{+}$and $\mathrm{K}^{+}$as in other treatments was given through infusions of $\mathrm{GluNaH}_{2} \mathrm{O}$ and $\mathrm{KHCO}_{3}$ in the duodenum.

${ }^{2}$ The maximal glucose equivalent corresponds to stochiometric calculations with 1 mol of C3 given 0.5 mol of glucose; 1 mol of Ala, Asp, Glu, Ser each given $0.5 \mathrm{~mol}$ of glucose; and $1 \mathrm{~mol}$ of Gly given $0.25 \mathrm{~mol}$ of glucose (VanMilgen, 2002).

${ }^{3}$ Glu: 6 carbons; C3: 6 carbons; Ala: 3 carbons; Asp: 4 carbons; Glu: 5 carbons; Gly: 2 carbons; Ser: 3 carbons. 
Glc treatments to maintain the anion-cation balance constant between treatments (i.e., $\mathrm{Na}^{+}$infused at 6.2 $\pm 0.21 \mathrm{~mol} / \mathrm{d}$ and $\mathrm{K}^{+}$infused at $2.7 \pm 0.10 \mathrm{~mol} / \mathrm{d}$ ). In the NEAAm treatment, because Glu was infused as GluNaH $\mathrm{H}_{2} \mathrm{O}$, providing $\mathrm{Na}^{+}$by infusion, $\mathrm{KHCO}_{3}$ was added to the duodenal infusion. (Table 2)

\section{Measurements, Sampling, and Analyses}

Measurements were made on the last $7 \mathrm{~d}$ of each $14-\mathrm{d}$ period. The amounts of feed offered and feed refusals were measured daily. The DM content of grass silage was determined daily to permit adjustment of the amount offered. Ruminal fluid was assayed for $\mathrm{pH}$ and for VFA and ammonia concentrations in samples taken at 0730,1130 , and $1530 \mathrm{~h}$ on $\mathrm{d} 11$. The $\mathrm{pH}$ was measured immediately. Ammonia and VFA samples were prepared, frozen, and analyzed as described by Rigout et al. (2003). Samples for VFA analysis were pooled.

Milk yield was recorded, and fat and protein contents were determined by infrared analysis (Milkoscan, Foss Electric, Hillerød, Denmark) at each milking. On d 13 at the morning milking, $100 \mathrm{~mL}$ of milk was taken for chemical analyses. Milk samples were used to analyze total $\mathrm{N}$, true protein $\mathrm{N}$, and casein (Kjeldahl), lactose and glucose concentrations (spectrophotometry), milk fatty acid (gas chromatography with butyl esters), according to the methods described by Hurtaud et al. (2000). Briefly, analysis of total N was immediately performed on milk samples stored at $4^{\circ} \mathrm{C}$. Milk samples were deproteinized and filtrated before to be frozen at $-20^{\circ} \mathrm{C}$ for analyses of true protein $\mathrm{N}$ (precipitation at $\mathrm{pH} 4.6$ with TCA) and of casein (precipitation at $\mathrm{pH}$ 4.6 with $10 \%$ acetic acid and $1 M$ sodium acetate) and for analysis of glucose (with $\mathrm{HClO}_{4}$ : vol/vol). Analysis of milk fatty acids was performed on milk samples stored at $-20^{\circ} \mathrm{C}$.

The effect of the treatments on Ra was measured on d 12 between $1315 \mathrm{~h}$ and $1530 \mathrm{~h}$. A solution of $\left[6,6{ }^{2} \mathrm{H}_{2}\right]$ glucose, 99 mol\% excess (mpe; Cambridge Isotope Laboratories, Andover, MA) was prepared with sterile saline for the priming dose injection and infusion (302 $\pm 2.2 \mathrm{mmol} / \mathrm{L}$ ) and was sterilized by filtration through a $0.22-\mu \mathrm{m}$ sterile disk filter (Millipore, Saint-Quentin en Yvelines, France). The priming dose was injected into one jugular vein $(13 \mathrm{mmol})$ and the solution was continuously infused at a constant rate of $23.56 \mathrm{mmol} / \mathrm{h}$ for 120 min with a syringe pump (Harvard Apparatus, Les Ulis, France). To check whether blood glucose coefficients of variation were less than $5 \%, 1 \mathrm{~mL}$ of blood was taken every $10 \mathrm{~min}$ (from $20 \mathrm{~min}$ before to $80 \mathrm{~min}$ after the beginning of the infusion) from the other jugular vein catheter so that a rapid measurement of blood glucose concentration could be made using a glucometer (LifeScan One Touch, Johnson \& Johnson Co., Milpitas, CA). In addition, blood samples were collected with syringes (S-Monovette, $7.5 \mathrm{~mL}$; Sarstedt, Nümbrecht, Germany) containing heparin (12 to 30 $\mathrm{IU} / \mathrm{mL}) 15$ and $10 \mathrm{~min}$ before injection of $\left[6,6-{ }^{2} \mathrm{H}_{2}\right] \mathrm{glu}-$ cose solution, to measure natural abundance, as well as during the plateau period, at 80, 90, 100, and $110 \mathrm{~min}$ after the priming injection/start of the infusion. Blood was centrifuged at $2,500 \times g$ for $10 \mathrm{~min}$ at $4^{\circ} \mathrm{C}$. Plasma samples to be analyzed for glucose concentration were stored at $-20^{\circ} \mathrm{C}$. Plasma samples for the measurement of $\left[6,6-{ }^{2} \mathrm{H}_{2}\right]$ glucose enrichments were deproteinized with an equal volume of $1.2 \mathrm{M}$ perchloric acid and filtered before being stored at $-20^{\circ} \mathrm{C}$. Preparation of samples before gas chromatography/mass spectrometry analysis to determine $\left[6,6-{ }^{2} \mathrm{H}_{2}\right]$ glucose enrichments was as described by Lemosquet et al. (2004b). Derivatization was performed with butaneboronic acid followed by addition of acetic anhydride. The isotopic enrichments of glucose, expressed as mpe above preinfusion values, were quantified for $m / z$ ions 297 and 299 in triplicate by gas chromatography/mass spectrometry in electron impact ionization mode (GC 8060 chromatograph coupled to a VG Platform II, Fisons Instruments, Altrincham, UK). A control plasma at 3.73 mpe was introduced in each batch of analysis (every 10 samples) with an inter-day coefficient of variation of $2.8 \%$.

On d 11 of each period, 6 jugular blood samples were taken every $2 \mathrm{~h}$, beginning at $0700 \mathrm{~h}$, for all metabolites, with additional samples taken every $\mathrm{h}(\mathrm{n}=12)$ for growth hormone $(\mathbf{G H})$ determinations. Samples were collected in syringes containing heparin (S-Monovette, $7.5 \mathrm{~mL}$; Sarstedt) for BHBA, glucose, lactate, total glycerol, NEFA, and urea analyses. Samples for insulin, GH, IGF-1, and cortisol determinations were collected in syringes containing 1.2 to $2 \mathrm{mg} / \mathrm{mL}$ of $\mathrm{K}_{2}$-EDTA (S-Monovette, $7.5 \mathrm{~mL}$; Sarstedt). Syringes containing $\mathrm{K}_{2}$-EDTA (S-Monovette, $2.5 \mathrm{~mL}$; Sarstedt) and 260 $\mu \mathrm{L}$ of the protease inhibitor aprotinine $(2,600 \mathrm{KIU}$ in sterile saline at $8.5 \mathrm{mg} / \mathrm{mL}$ of $\mathrm{NaCl}$; Antagosan, Hoechst Marion Roussel GmbH, Marbourg, Germany) were used to collect blood for determination of glucagon concentrations. Blood samples were centrifuged at $2,500 \times g$ for 10 min at $4^{\circ} \mathrm{C}$. For AA analyses, plasma was deproteinized with $50 \% \mathrm{vol} / \mathrm{vol}$ sulfosalicylic acid and supernatant collected after centrifugation at 2,000 $\times g$ for 15 min. Plasma was also deproteinized with $50 \%$ (vol/vol) perchloric perchloric acid, followed by filtration to analyze acetate, BHBA, and lactate. All samples were stored at $-20^{\circ} \mathrm{C}$ until analysis, except for samples for hormone analysis, which were stored at $-80^{\circ} \mathrm{C}$.

Samples for analysis of AA, acetate, BHBA, lactate, and total glycerol were pooled per cow and per period 
before the analyses. Plasma-free AA were analyzed by chromatography on a cationic exchange resin column, ion exchange chromatography followed by ninhydrin reaction (Hurtaud et al., 2000) on a Biotronik LC 3000 (Biotronik GmbH, Maintal, Germany). Other plasma metabolites were measured on a multiparameter analyzer (Kone Instruments Corp., Espoo, Finland) using the following procedures. Acetate was analyzed using the acetyl-CoA synthase, citrate synthase, and malate dehydrogenase method (Sigma-Aldrich, Saint-Quentin Fallavier, France). Concentrations of BHBA were analyzed using BHBA dehydrogenase (Sigma-Aldrich). Enzymatic kits were used for glucose (hexokinase, GLUC HK 07 3672, Roche Diagnostics, Meylan, France), for L-lactate (lactate oxidase and peroxidase; Lactate-PAP 61192, BioMérieux S.A., Marcy l'Etoile, France), for NEFA (acetyl-CoA synthase, acyl-CoA oxidase and peroxidase; NEFA C Wako kit, Oxoid S.A., Dardilly, France), for total glycerol (lipase, glycerol kinase, glycerol-3-P oxidase and peroxidase, GPO PAP, Biotrol, Earth City, MO), and for urea (urease and glutamate dehydrogenase, Urée UV cinétique; Kone Diagnostics, Evry, France).

Insulin, GH, and IGF-1 were analyzed by RIA as described by Lemosquet et al. (2004a). Glucagon was analyzed using a RIA kit (Cliniscience, Linco Research, St. Charles, MO) and cortisol by the EIA method (Negrao and Marnet, 2006).

\section{Calculations and Statistical Analyses}

Whole-body glucose Ra was determined with the following equation, assuming steady-state:

$$
\mathrm{Ra}=\mathrm{F} \times\left(\frac{\mathrm{IEinf}}{\mathrm{IEp}}-1\right),
$$

where $\mathrm{F}$ is the $\left[6,6-{ }^{2} \mathrm{H}_{2}\right]$ glucose infusion rate $(\mathrm{mol} / \mathrm{h})$, IEinf is the isotopic enrichment of the infusate (99 mpe), and IEp (in mpe) is the isotopic enrichment of plasma in $\left[6,6-{ }^{2} \mathrm{H}_{2}\right]$ glucose.

The mean values obtained for each cow per period were used in the statistical analyses. Each parameter was analyzed using PROC MIXED of SAS (2004) according to the following statistical model: $\mathrm{Y}_{\mathrm{ijk}}=\mu+$ $\mathrm{COW}_{\mathrm{i}}+\mathrm{PERIOD}_{\mathrm{j}}+\mathrm{TREATMENT}_{\mathrm{k}}+\mathrm{e}_{\mathrm{ijk}}$ with COW considered as a fixed effect. Results were expressed as least square means with standard errors of means. Differences among treatments were compared using 3 orthogonal contrasts. The first contrast was used to test the effect of infusions (control vs. infusions: -3 Ctrl, 1 Glc, 1 C3, 1 NEAAm). The second contrast was used to compare the effect of duodenal Glc and ruminal $\mathrm{C} 3$ with the effect of infused NEAAm (1 Glc, 1 C3, -2 NEAAm). The third contrast was used to compare the effect of Glc with that of C3 (1 Glc and -1 C3). Statistical significance was set at $P \leq 0.05$ and tendency at $0.05<P \leq 0.10$.

\section{RESULTS}

\section{Effect of Infusions on Intake, Milk, and Digestive Parameters}

The DMI and dietary supplies of $\mathrm{DE}, \mathrm{NE}_{\mathrm{L}}$, and PDI (Table 3) decreased $(P=0.04)$ with the infusions of nutrients. However, total DE supply (diet + infusion) tended to increase $(P=0.08)$ with infusions of the 3 nutrients.

The milk yield and composition responses to the supplemental energy depended on the type of nutrients infused. Milk yield decreased $(P<0.001)$ during NEAAm infusion compared with $\mathrm{C} 3$ and Glc $(-2.65$ $\mathrm{kg} / \mathrm{d}$ ) and did not differ between Glc and C3 (Table 4). Milk fat content and yield decreased $(P<0.001)$ for Glc and C3 compared with NEAAm and did not differ between Glc and C3. As a result, 4\% FCM was decreased for Glc and C3 compared with NEAAm. Milk protein content was not affected by the treatments, but milk protein yield followed the same trend as milk yield variation and was lower $(P<0.001)$ for NEAAm compared with Glc and $\mathrm{C} 3$. The casein to true protein ratio was not affected by the treatments.

As designed, cows in the Ctrl treatment were in negative $\mathrm{NE}_{\mathrm{L}}$ balance $(-3.2 \mathrm{Mcal} / \mathrm{d}$, at $88 \%$ of INRA requirement, Table 3) and in positive protein balance $(+327 \mathrm{~g}$ of $\mathrm{PDI} /$ d; i.e., $122 \%$ of INRA requirement). In the Glc and C3 treatments (diet plus infusion), cows were near $\mathrm{NE}_{\mathrm{L}}$ balance $(0.7$ and $-0.4 \mathrm{Mcal} / \mathrm{d}$, respectively) and in positive PDI balance $(+249 \mathrm{~g} / \mathrm{d}$ and 226 $\mathrm{g} / \mathrm{d}$, respectively). As in the Ctrl, during NEAAm infusion, cows were in negative $\mathrm{NE}_{\mathrm{L}}$ balance $(-2.6 \mathrm{Mcal} / \mathrm{d})$ considering that the NEAAm infusion provided 2.74 Mcal of $\mathrm{NE}_{\mathrm{L}}$. Dietary intake in the NEAAm treatment provided enough PDI to maintain cows in positive PDI balance $(+318 \mathrm{~g}$ of PDI/d with diet alone). The amount of NEAAm $(1,445 \mathrm{~g} / \mathrm{d})$ required to be isocaloric to Glc and C3 infusions on a DE basis greatly increased the total PDI supply (+83.3\% with diet plus infusion). However, this intestinal AA supplement was completely unbalanced in terms of AA composition because only NEAA were infused.

Infusions of the 3 nutrients increased $(P=0.03)$ total VFA concentrations in the rumen (Table 5) but only C3 changed the molar proportion of VFA, mainly by increasing the percentage of ruminal propionic acid and decreasing the percentage of ruminal acetic acid. The 
Table 3. Effect of nutrient infusions on feed, energy, and protein intakes ${ }^{1}$

\begin{tabular}{|c|c|c|c|c|c|c|c|c|}
\hline \multirow[b]{2}{*}{ Item } & \multicolumn{4}{|c|}{ Treatment $^{2}$} & \multirow[b]{2}{*}{ SEM } & \multicolumn{3}{|c|}{$P$-value ${ }^{3}$} \\
\hline & Ctrl & Glc & C3 & NEAAm & & Infusions & $\begin{array}{c}\text { Glc and C3 } \\
\text { vs. NEAAm }\end{array}$ & Glc vs. C3 \\
\hline DMI, kg DM/d & 15.6 & 15.1 & 14.6 & 14.4 & 0.30 & 0.04 & 0.27 & 0.24 \\
\hline $\mathrm{DE}^{4} \mathrm{Mcal} / \mathrm{d}$ & 51.9 & 50.4 & 48.6 & 48.1 & 0.95 & 0.04 & 0.26 & 0.24 \\
\hline $\mathrm{NE}_{\mathrm{L}},{ }^{4} \mathrm{Mcal} / \mathrm{d}$ & 23.5 & 22.6 & 21.7 & 21.3 & 0.55 & 0.05 & 0.28 & 0.27 \\
\hline \multicolumn{9}{|l|}{ Diet + infusions } \\
\hline $\mathrm{DE}, \mathrm{Mcal} / \mathrm{d}$ & 51.9 & 55.5 & 53.8 & 53.2 & 0.95 & 0.08 & 0.27 & 0.25 \\
\hline $\mathrm{NE}_{\mathrm{L}}, \mathrm{Mcal} / \mathrm{d}$ & 23.5 & 26.5 & 25.4 & 24.1 & 0.55 & 0.03 & 0.03 & 0.23 \\
\hline PDI, g/d & 1,826 & 1,790 & 1,748 & 3,178 & 21.3 & $<0.001$ & $<0.001$ & $<0.21$ \\
\hline \multicolumn{9}{|c|}{ Net balances (diet + infusions $)^{4}$} \\
\hline $\mathrm{NE}_{\mathrm{L}}, \mathrm{Mcal} / \mathrm{d}$ & -3.2 & 0.7 & -0.4 & -2.6 & 0.66 & 0.02 & 0.02 & 0.25 \\
\hline PDI, g/d & 327 & 249 & 226 & 1,764 & 34.2 & $<0.001$ & $<0.001$ & 0.65 \\
\hline
\end{tabular}

${ }^{1}$ Data are presented as means with SEM, given for $\mathrm{n}=4 ; 16$ observations.

${ }^{2} \mathrm{Ctrl}=$ water infusions; Glc $=7.7 \mathrm{~mol}$ of glucose $/ \mathrm{d}$ into the duodenum; $\mathrm{C} 3=14.1 \pm 0.1 \mathrm{~mol}$ of propionic acid $/ \mathrm{d}$ into the rumen; NEAAm $=\mathrm{a}$ mixture of 5 nonessential amino acids infused into the duodenum $(\mathrm{Ala}=1.6 \mathrm{~mol} / \mathrm{d} ; \mathrm{Asp}=0.60 \mathrm{~mol} / \mathrm{d} ; \mathrm{Glu}=5.94 \mathrm{~mol} / \mathrm{d} ; \mathrm{Gly}=1.22 \mathrm{~mol} / \mathrm{d}$; Ser $=2.45 \mathrm{~mol} / \mathrm{d}$ ).

${ }^{3}$ Probability corresponding to the null hypothesis with the 3 contrasts. Contrast infusions: Ctrl versus (Glc and C3 and NEAAm); contrast Glc and C3 versus NEAAm; contrast Glc versus C3.

${ }^{4}$ Estimated with INRA (1989).

${ }^{5} \mathrm{PDI}=$ protein truly digested in the small intestine (INRA, 1989).

infusion of NEAAm increased the ammonia concentration in the rumen and produced a lower rumen $\mathrm{pH}$, probably because no buffer was infused into the rumen.

\section{Whole-Body Glucose Rate of Appearance and Milk Lactose}

During the infusion of $\left[6,6-{ }^{2} \mathrm{H}_{2}\right]$ glucose, plasma glucose concentrations (Table 6) and isotopic enrichment were maintained at a steady state $(\mathrm{CV}<5 \%)$. The highest coefficient of variation obtained during a treatment period was $4.1 \%$ for plasma glucose concentration and $4.8 \%$ for isotopic enrichment. The 3 infusions of nutrients (Table 6 ) increased the Ra but the increase was higher $(P<0.01)$ during Glc and $\mathrm{C} 3$ than during NEAAm and it was also higher $(P<0.001)$ during Glc treatment than during C3 alone. The same order of responses (Table 6) was observed if Ra was expressed per megacalorie of total DE supply (diet + infusion).

Lactose yield (Table 6) decreased with milk yield (Table 4) in NEAAm compared with Glc and C3 and

Table 4. Effects of nutrient infusions on milk yield and composition ${ }^{1}$

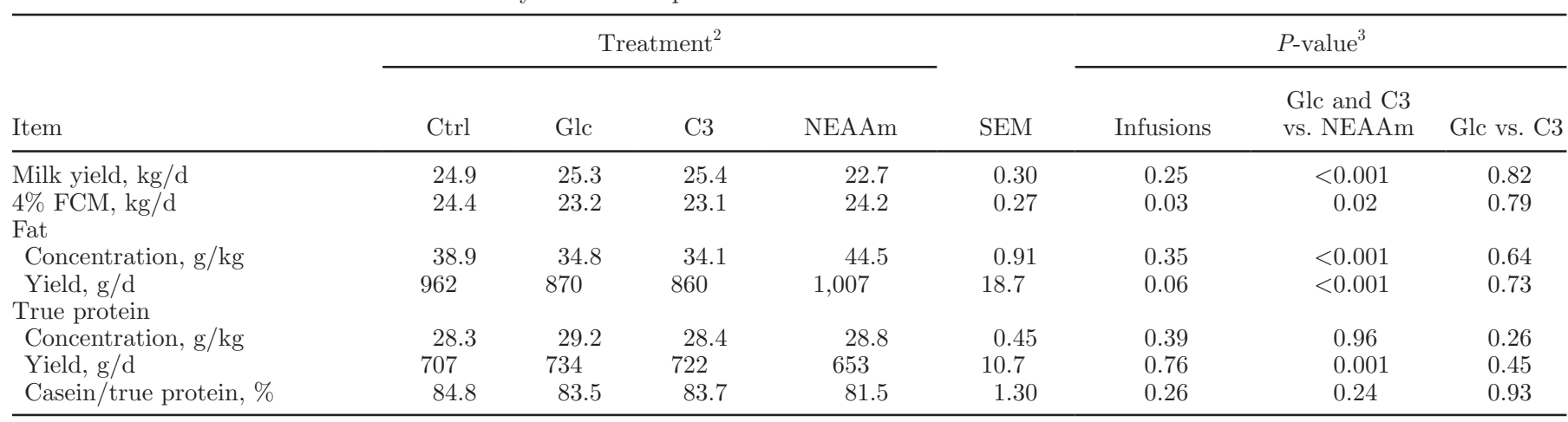

${ }^{1}$ Data are presented as means with SEM, given for $\mathrm{n}=4 ; 16$ observations.

${ }^{2} \mathrm{Ctrl}=$ water infusions; Glc $=7.7 \mathrm{~mol}$ of glucose $/ \mathrm{d}$ into the duodenum; $\mathrm{C} 3=14.1 \pm 0.1 \mathrm{~mol}$ of propionic acid $/ \mathrm{d}$ into the rumen; NEAAm $=$ mixture of 5 nonessential amino acids infused into the duodenum $(\mathrm{Ala}=1.6 \mathrm{~mol} / \mathrm{d} ; \mathrm{Asp}=0.60 \mathrm{~mol} / \mathrm{d} ; \mathrm{Glu}=5.94 \mathrm{~mol} / \mathrm{d}$; Gly $=1.22 \mathrm{~mol} / \mathrm{d}$; Ser $=2.45 \mathrm{~mol} / \mathrm{d})$.

${ }^{3}$ Probability corresponding to the null hypothesis with the 3 contrasts. Contrast infusions: Ctrl versus (Glc and C3 and NEAAm); contrast Glc and $\mathrm{C} 3$ versus NEAAm; contrast Glc versus C3. 
Table 5. Effect of nutrient infusions on rumen $\mathrm{pH}$, volatile fatty acid, and ammonia concentrations ${ }^{1}$

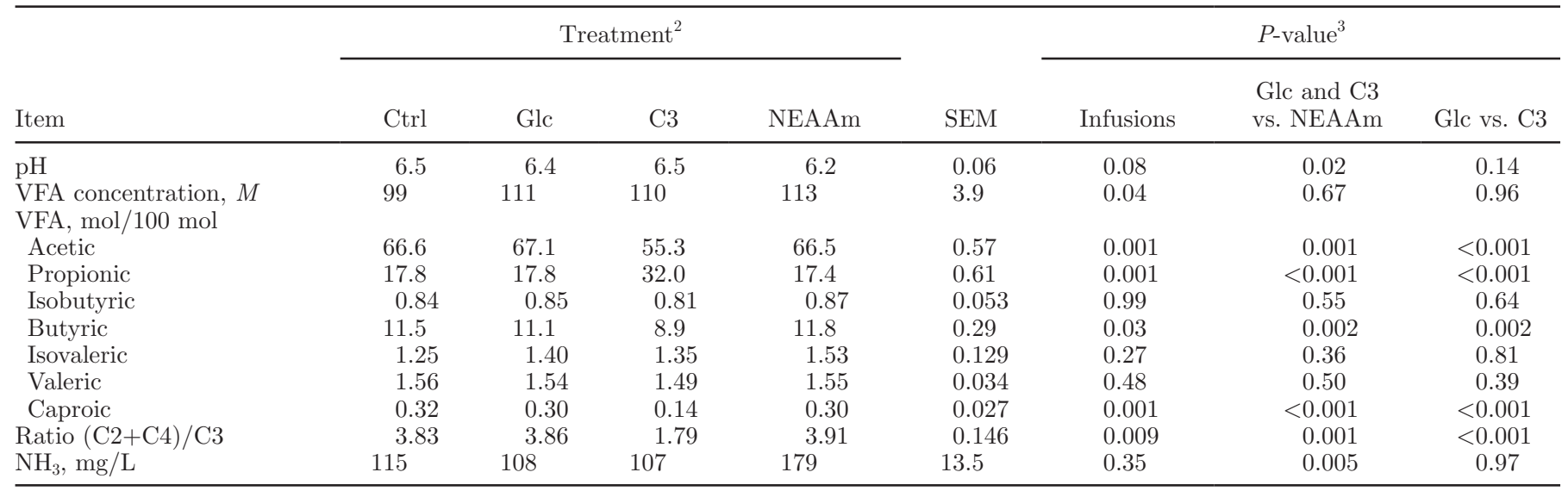

${ }^{1}$ Data are presented as means with SEM, given for $\mathrm{n}=4 ; 16$ observations.

${ }^{2} \mathrm{Ctrl}=$ water infusions; Glc $=7.7 \mathrm{~mol}$ of glucose $/ \mathrm{d}$ into the duodenum; $\mathrm{C} 3=14.1 \pm 0.1 \mathrm{~mol}$ of propionic acid $/ \mathrm{d}$ into the rumen; NEAAm $=$ mixture of 5 nonessential amino acids infused into the duodenum $(\mathrm{Ala}=1.6 \mathrm{~mol} / \mathrm{d} ; \mathrm{Asp}=0.60 \mathrm{~mol} / \mathrm{d} ; \mathrm{Glu}=5.94 \mathrm{~mol} / \mathrm{d}$; Gly $=1.22 \mathrm{~mol} / \mathrm{d}$; Ser $=2.45 \mathrm{~mol} / \mathrm{d})$.

${ }^{3}$ Probability corresponding to the null hypothesis with the 3 contrasts. Contrast infusions: Ctrl versus (Glc and C3 and NEAAm); contrast Glc and $\mathrm{C} 3$ versus NEAAm; contrast Glc versus C3.

the lactose concentration in milk tended $(P=0.06)$ to increase. The ratio of milk lactose yield to Ra decreased $(P<0.01)$ with the infusions. It was lower $(P=0.02)$ in Glc than in C3. Glucose concentration in milk decreased $(P<0.001)$ with NEAAm compared with Glc and $\mathrm{C} 3$ and it was lower $(P=0.02)$ during Glc treatment than during $\mathrm{C} 3$ treatment.

\section{Energy Metabolites and Hormone Concentrations}

During the day of the metabolite measurements (Table 7), plasma glucose concentration tended $(P=$
$0.09)$ to increase with the infusions of nutrients because it tended $(P=0.08)$ to be higher during Glc and C3 compared with NEAAm. Although not as strong, these variations were similar to those observed during the infusion of $\left[6,6-{ }^{2} \mathrm{H}_{2}\right]$ glucose. Plasma lactate concentration greatly increased $(P<0.001)$ in NEAAm compared with Glc and C3.

The plasma concentration of total glycerol decreased $(P<0.01)$ with the infusions, and this trend was more marked $(P=0.06)$ in Glc compared with $\mathrm{C} 3$ (Table 7). The plasma concentrations of NEFA, acetate, and BHBA were lower $(P<0.001)$ with Glc and C3 than

Table 6. Effect of nutrient infusion on whole-body glucose rate of appearance $(\mathrm{Ra})^{1}$

\begin{tabular}{|c|c|c|c|c|c|c|c|c|}
\hline \multirow[b]{2}{*}{ Item } & \multicolumn{4}{|c|}{ Treatment $^{2}$} & \multirow[b]{2}{*}{ SEM } & \multicolumn{3}{|c|}{$P$-value ${ }^{3}$} \\
\hline & Ctrl & Glc & C3 & NEAAm & & Infusions & $\begin{array}{l}\text { Glc and C3 } \\
\text { vs. NEAAm }\end{array}$ & Glc vs. C3 \\
\hline Plasma glucose, $\mathrm{m} M$ & 3.70 & 4.04 & 4.00 & 3.80 & 0.068 & 0.02 & 0.04 & 0.73 \\
\hline $\mathrm{Ra}, \mathrm{mmol} / \mathrm{h}$ & 502 & 745 & 600 & 576 & 17.9 & $<0.001$ & 0.005 & 0.001 \\
\hline $\mathrm{Ra}: \mathrm{DE},{ }^{4} \mathrm{~mol} / \mathrm{Mcal}$ & 0.23 & 0.32 & 0.27 & 0.26 & 0.086 & 0.002 & 0.01 & 0.004 \\
\hline \multicolumn{9}{|l|}{ Milk lactose $^{5}$} \\
\hline Glucose in milk, $\mathrm{m} M$ & 0.59 & 0.55 & 0.66 & 0.46 & 0.024 & 0.28 & $<0.001$ & 0.02 \\
\hline Lactose: $\mathrm{Ra}^{6}$ & 0.56 & 0.38 & 0.47 & 0.46 & 0.019 & 0.002 & 0.18 & 0.02 \\
\hline
\end{tabular}

${ }^{1}$ Data are presented as means with SEM, given for $\mathrm{n}=4 ; 16$ observations.

${ }^{2} \mathrm{Ctrl}=$ water infusions; Glc $=7.7 \mathrm{~mol}$ of glucose $/ \mathrm{d}$ in the duodenum; $\mathrm{C} 3=14.1 \pm 0.1 \mathrm{~mol}$ of propionic acid $/ \mathrm{d}$ into the rumen; NEAAm $=$ mixture of 5 nonessential amino acids infused into the duodenum $(\mathrm{Ala}=1.6 \mathrm{~mol} / \mathrm{d} ; \mathrm{Asp}=0.60 \mathrm{~mol} / \mathrm{d} ; \mathrm{Glu}=5.94 \mathrm{~mol} / \mathrm{d} ; \mathrm{Gly}=1.22 \mathrm{~mol} / \mathrm{d}$; Ser $=2.45 \mathrm{~mol} / \mathrm{d})$.

${ }^{3}$ Probability corresponding to the null hypothesis with the 3 contrasts. Contrast infusions: Ctrl versus (Glc and C3 and NEAAm); contrast Glc and C3 versus NEAAm; contrast Glc versus C3.

${ }^{4}$ Ratio between Ra (in mol/d) and total DE supply (diet + infusions) in Mcal/d.

${ }^{5}$ Monohydrated lactose (molecular weight $=360.3 \mathrm{~g} / \mathrm{mol}$ ).

${ }^{6} \mathrm{Ratio}$ between lactose (in $\mathrm{mmol} / \mathrm{h}$ of carbons) and $\mathrm{Ra}$ (in $\mathrm{mmol} / \mathrm{h}$ of carbons). 
Table 7. Effect of nutrient infusions on energy metabolites and hormones in plasma ${ }^{1}$

\begin{tabular}{|c|c|c|c|c|c|c|c|c|}
\hline Item & \multicolumn{4}{|c|}{ Treatment $^{2}$} & SEM & \multicolumn{3}{|c|}{$P$-value ${ }^{3}$} \\
\hline Lactate, $\mathrm{m} M$ & 0.45 & 0.29 & 0.45 & 1.56 & 0.083 & 0.02 & $<0.001$ & 0.22 \\
\hline Total glycerol, $\mu M$ & 104 & 79 & 89 & 89 & 3.1 & 0.002 & 0.22 & 0.06 \\
\hline NEFA, $\mu M$ & 110 & 59 & 69 & 133 & 8.5 & 0.05 & 0.001 & 0.42 \\
\hline Glucagon, $\mathrm{pg} / \mathrm{mL}$ & 97 & 94 & 91 & 362 & 41.7 & 0.13 & 0.002 & 0.96 \\
\hline Ratio insulin:glucagon & 8.09 & 9.74 & 11.00 & 3.56 & 1.12 & 0.99 & 0.003 & 0.46 \\
\hline Cortisol, $\mathrm{ng} / \mathrm{mL}$ & 7.5 & 9.1 & 9.2 & 8.4 & 0.79 & 0.18 & 0.47 & 0.90 \\
\hline $\mathrm{GH},{ }^{4} \mathrm{ng} / \mathrm{mL}$ & 4.62 & 4.14 & 4.44 & 4.64 & 0.47 & 0.71 & 0.57 & 0.67 \\
\hline $\mathrm{IGF}-1, \mathrm{ng} / \mathrm{mL}$ & 146 & 191 & 161 & 192 & 11.6 & 0.04 & 0.30 & 0.11 \\
\hline
\end{tabular}

${ }^{1}$ Data are presented as means with SEM, given for $\mathrm{n}=4 ; 16$ observations.

${ }^{2} \mathrm{Ctrl}=$ water infusions; Glc $=7.7 \mathrm{~mol}$ of glucose $/ \mathrm{d}$ into the duodenum; $\mathrm{C} 3=14.1 \pm 0.1 \mathrm{~mol}$ of propionic acid $/ \mathrm{d}$ into the rumen; $\mathrm{NEAAm}=$ mixture of 5 nonessential amino acids infused into the duodenum $(\mathrm{Ala}=1.6 \mathrm{~mol} / \mathrm{d} ; \mathrm{Asp}=0.60 \mathrm{~mol} / \mathrm{d} ; \mathrm{Glu}=5.94 \mathrm{~mol} / \mathrm{d} ; \mathrm{Gly}=1.22 \mathrm{~mol} / \mathrm{d}$; Ser $=2.45 \mathrm{~mol} / \mathrm{d})$

${ }^{3}$ Probability corresponding to the null hypothesis with the 3 contrasts. Contrast infusions: Ctrl versus (Glc and C3 and NEAAm); contrast Glc and C3 versus NEAAm; contrast Glc versus C3.

${ }^{4}$ Growth hormone.

for NEAAm, but there was no difference between Glc and $\mathrm{C} 3$.

Plasma insulin concentrations were not affected by any of the treatments, whereas plasma glucagon concentrations increased $(P<0.01)$ during NEAAm compared with Glc and C3 infusions. Plasma concentrations of cortisol and GH were not affected by any of the treatments either. Plasma concentrations of IGF-1 increased with the infusions but were not affected by the type of nutrients infused.

\section{Milk Fatty Acid Composition}

Infusions of the 3 nutrients decreased $(P<0.01)$ the yield of short fatty acids (sum of $\mathrm{C}_{4}$ to $\mathrm{C}_{8}$; Table 8), with the decrease being larger $(P<0.01)$ for Glc and C3 than for NEAAm for the yield of short fatty acids. The yield of medium-chain fatty acids (i.e., sum of $\mathrm{C}_{10}$ to $\mathrm{C}_{14}$ ) was not affected by nutrient infusions, but tended $(P=0.06)$ to be higher during Glc compared with C3. The yield of the sum of $\mathrm{C}_{16: 1}$ and $\mathrm{C}_{16: 0}$ increased, on average, with the infusions $(+32 \mathrm{~g} / \mathrm{d})$. It was linked to a higher yield in NEAAm (contrast Glc and C3 vs. NEAAm: $-42.5 \mathrm{~g} / \mathrm{d} ; P<0.01)$ and in Glc compared with $\mathrm{C} 3(+30 \mathrm{~g} / \mathrm{d} ; P=0.05)$. In contrast, the yield of all $\mathrm{C}_{18}$ were reduced with Glc and $\mathrm{C} 3$ compared with NEAAm. The yield of the sum of odd fatty acids increased during the $\mathrm{C} 3$ treatment (contrast Glc and C3 vs. NEAAm at $P=0.09$ and contrast Glc vs. $\mathrm{C} 3$ at $P$ $<0.01:+6.8 \mathrm{~g} / \mathrm{d})$.

Table 8. Effect of nutrient infusions on milk fatty acid production ${ }^{1}$

\begin{tabular}{|c|c|c|c|c|c|c|c|c|}
\hline \multirow[b]{2}{*}{ Sum, g/d } & \multicolumn{4}{|c|}{ Treatment $^{2}$} & \multirow[b]{2}{*}{ SEM } & \multicolumn{3}{|c|}{$P$-value ${ }^{3}$} \\
\hline & Ctrl & Glc & C3 & NEAAm & & Infusions & $\begin{array}{l}\text { Glc and C3 } \\
\text { vs. NEAAm }\end{array}$ & Glc vs. C3 \\
\hline $\mathrm{C}_{4}$ to $\mathrm{C}_{8}$ & 50.6 & 41.5 & 39.3 & 47.3 & 1.03 & 0.01 & 0.002 & 0.18 \\
\hline $\mathrm{C}_{10}$ to $\mathrm{C}_{14}$ & 188 & 193 & 174 & 181 & 5.8 & 0.45 & 0.66 & 0.06 \\
\hline $\mathrm{C}_{16: 1}+\mathrm{C}_{16: 0}$ & 329 & 362 & 332 & 390 & 8.5 & 0.02 & 0.003 & 0.05 \\
\hline All $\mathrm{C}_{18}$ & 310 & 195 & 230 & 305 & 13.8 & 0.06 & 0.002 & 0.12 \\
\hline
\end{tabular}

${ }^{1}$ Data are presented as means with SEM, given for $\mathrm{n}=4 ; 16$ observations.

${ }^{2} \mathrm{Ctrl}=$ water infusions; Glc $=7.7 \mathrm{~mol}$ of glucose $/ \mathrm{d}$ into the duodenum; $\mathrm{C} 3=14.1 \pm 0.1 \mathrm{~mol}$ of propionic acid $/ \mathrm{d}$ into the rumen; NEAAm $=$ mixture of 5 nonessential amino acids infused into the duodenum $(\mathrm{Ala}=1.6 \mathrm{~mol} / \mathrm{d}$; Asp $=0.60 \mathrm{~mol} / \mathrm{d} ; \mathrm{Glu}=5.94 \mathrm{~mol} / \mathrm{d} ; \mathrm{Gly}=1.22 \mathrm{~mol} / \mathrm{d}$; Ser $=2.45 \mathrm{~mol} / \mathrm{d})$.

${ }^{3}$ Probability corresponding to the null hypothesis with the 3 contrasts. Contrast infusions: Ctrl versus (Glc and C3 and NEAAm); contrast Glc and C3 versus NEAAm; contrast Glc versus C3. 
Table 9. Effect of nutrient infusions on milk fatty acid composition ${ }^{1}$

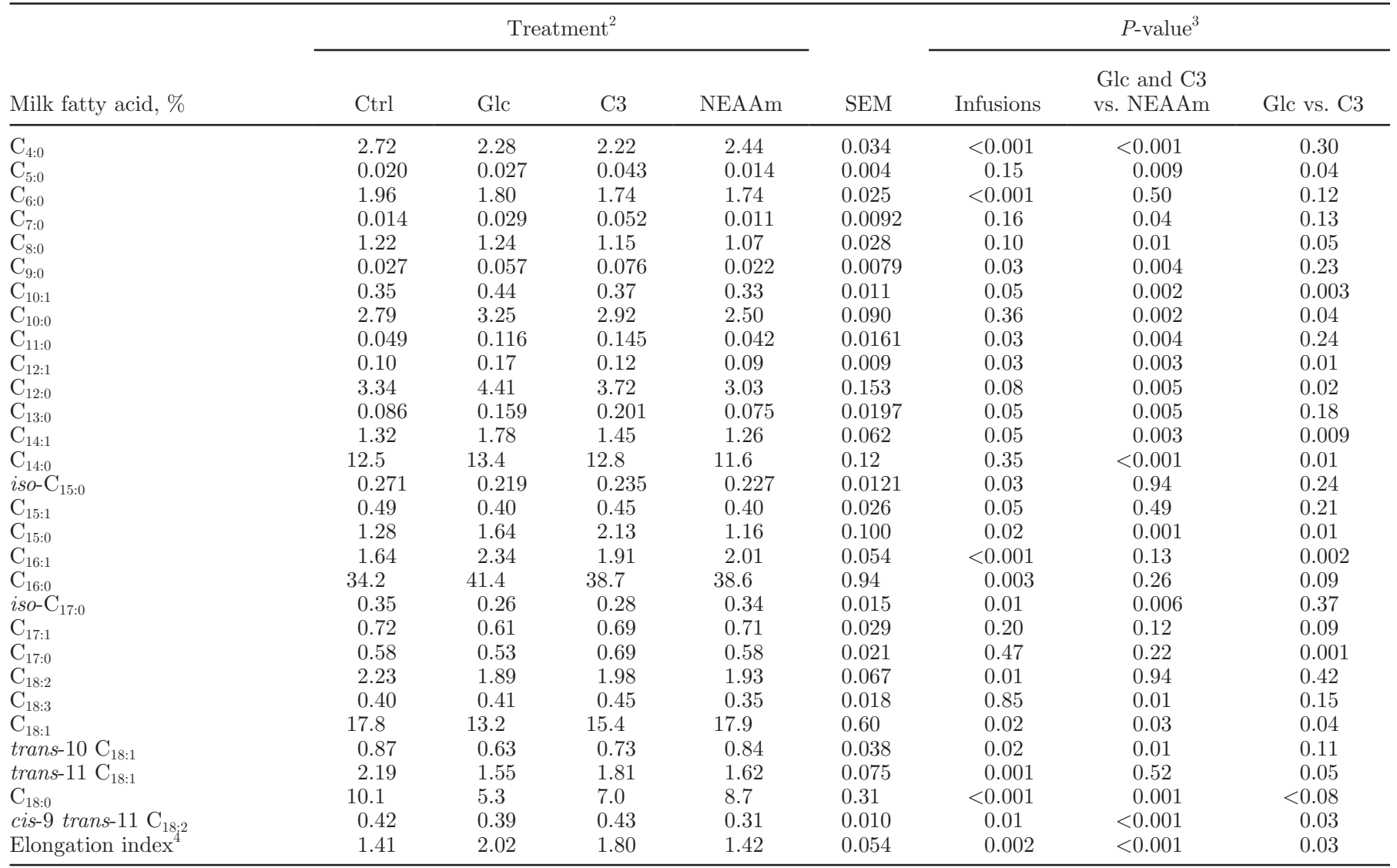

${ }^{1}$ Data are presented as means with SEM, given for $\mathrm{n}=4 ; 16$ observations.

${ }^{2} \mathrm{Ctrl}=$ water infusions; $\mathrm{Glc}=7.7 \mathrm{~mol}$ of glucose $/ \mathrm{d}$ into the duodenum; $\mathrm{C} 3=14.1 \pm 0.1 \mathrm{~mol}$ of propionic acid $/ \mathrm{d}$ into the rumen; NEAAm $=$ mixture of 5 nonessential amino acids infused into the duodenum $(\mathrm{Ala}=1.6 \mathrm{~mol} / \mathrm{d} ; \mathrm{Asp}=0.60 \mathrm{~mol} / \mathrm{d} ; \mathrm{Glu}=5.94 \mathrm{~mol} / \mathrm{d}$; Gly $=1.22 \mathrm{~mol} / \mathrm{d}$; Ser $=2.45 \mathrm{~mol} / \mathrm{d})$.

${ }^{3}$ Probability corresponding to the null hypothesis with the 3 contrasts. Contrast infusions: Ctrl versus (Glc and C3 and NEAAm); contrast Glc and $\mathrm{C} 3$ versus NEAAm; contrast Glc versus C3.

${ }^{4}$ Calculated as the ratio of $\left(\mathrm{C}_{10: 1}+\mathrm{C}_{10}+\mathrm{C}_{12: 1}+\mathrm{C}_{12}\right)$ to $\left(\mathrm{C}_{4}+\mathrm{C}_{6}\right)$.

The variations in the percentages of individual fatty acids (Table 9) in milk generally reflected the variation observed in fatty acid yield. More specifically, infusions of the 3 nutrients decreased $(P<0.01)$ the percentage of $\mathrm{C}_{4: 0}$ and of $\mathrm{C}_{6: 0}$ (Table 9), with the decrease in the percentage of $\mathrm{C}_{4: 0}$ being larger $(P<0.01)$ for Glc and C3 than for NEAAm. All the percentages of $\mathrm{C}_{10}$ through $\mathrm{C}_{14: 1}$ were higher in Glc and $\mathrm{C} 3$ compared with NEAAm, and the percentages of $\mathrm{C}_{10: 1}, \mathrm{C}_{10: 0}, \mathrm{C}_{12: 1}$, $\mathrm{C}_{12: 0}, \mathrm{C}_{14: 1}$, and $\mathrm{C}_{14: 0}$ were also higher in Glc than in C3. The percentages of $\mathrm{C}_{16: 1}$ and $\mathrm{C}_{16: 0}$ were increased by the infusions and were higher in Glc compared with C3 but not in NEAAm, which showed a different trend from $\mathrm{C}_{16}$ yield variations. The percentages of $\mathrm{C}_{18: 0}$ and $\mathrm{C}_{18: 1}$ were reduced during Glc and C3 compared with NEAAm $(-30 \%$ and $-20 \%$, respectively), with a greater reduction during Glc relative to C3 $(-25 \%$ and $-14 \%$, respectively); however, this was not the case for $\mathrm{C}_{18}$ yield. The percentage of trans-10 $\mathrm{C}_{18: 1}$ decreased
$(P=0.01)$ with Glc and C3 compared with NEAAm (Table 9$)$. Infusions also decreased $(P<0.01)$ the percentage of trans-11 $\mathrm{C}_{18: 1}$, which was lower $(P=0.05)$ in Glc compared with C3. NEAAm infusions decreased $(P$ $<0.01)$ Cis-9 trans-11 $\mathrm{C}_{18: 2}$ compared with Glc and C3, but the concentrations were lower $(P=0.03)$ for Glc than for C3. Overall, the elongation index $\left[\left(\mathrm{C}_{10: 1}+\mathrm{C}_{10}\right.\right.$ $\left.\left.+\mathrm{C}_{12: 1}+\mathrm{C}_{12}\right) /\left(\mathrm{C}_{4: 0}+\mathrm{C}_{6: 0}\right)\right]$ was higher in Glc than in C3 and was higher in Glc and C3 than in NEAAm.

\section{Urea and AA Concentrations}

Plasma concentrations of urea (Table 10) was affected differently by the infusions: the concentration increased $(P<0.001) 2$-fold in NEAAm compared with Glc and C3. Plasma concentrations of infused NEAA increased substantially $(P<0.001)$ with NEAAm: compared with Ctrl, the concentration of Ala was increased 3.5-fold, Asp 4-fold, Glu 3-fold, Gly 5.6-fold and Ser 20.9-fold. 
Table 10. Effect of nutrient infusions on plasma urea and AA concentrations ${ }^{1}$

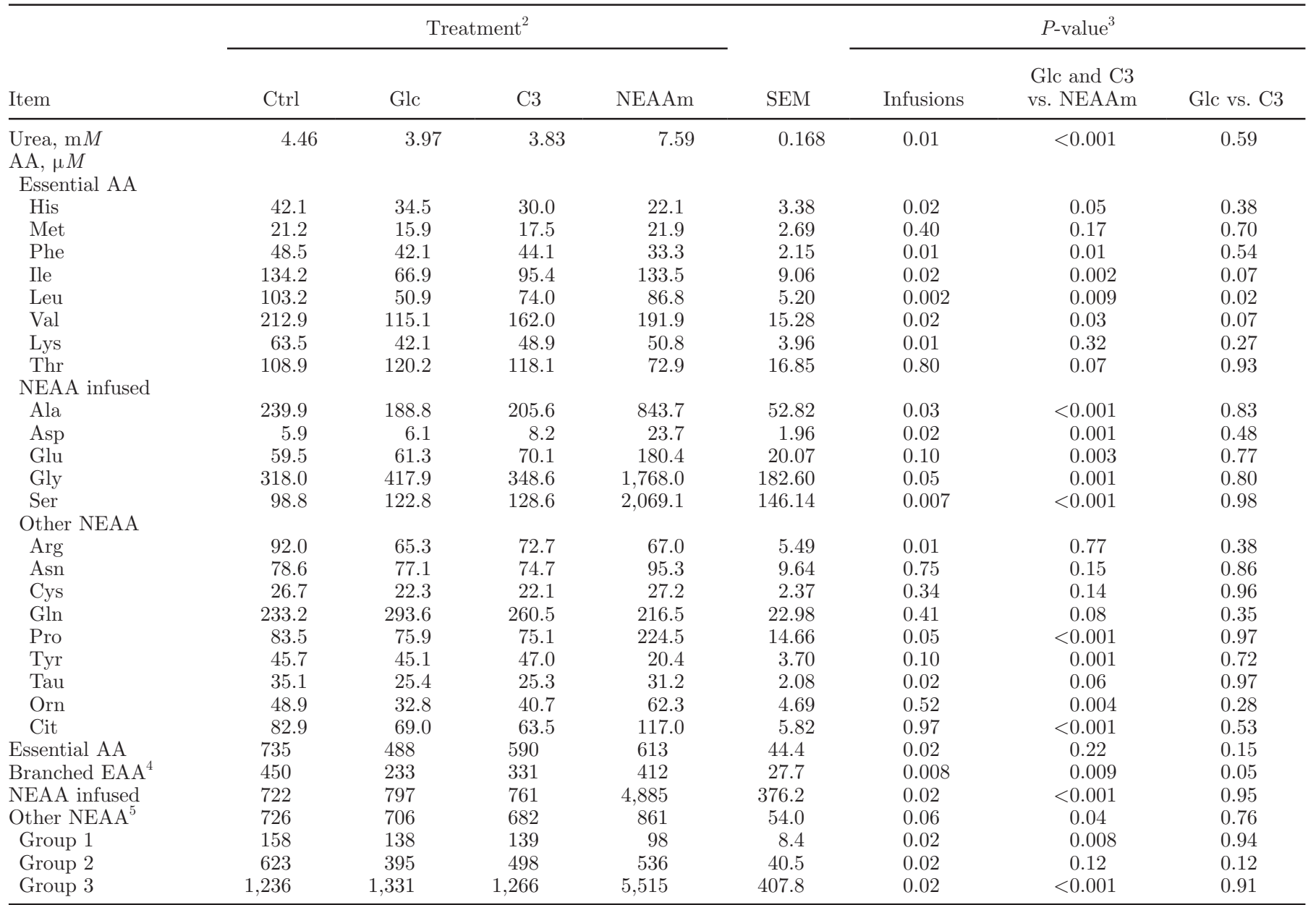

${ }^{1}$ Means presented with SEM, given for $\mathrm{n}=4 ; 16$ observations.

${ }^{2} \mathrm{Ctrl}=$ water infusions; Glc $=7.7 \mathrm{~mol}$ of glucose $/ \mathrm{d}$ into the duodenum; $\mathrm{C} 3=14.1 \pm 0.1 \mathrm{~mol}$ of propionic acid/d into the rumen; NEAAm: a mixture of 5 nonessential amino acids (NEAA) infused into the duodenum (Ala $=1.6 \mathrm{~mol} / \mathrm{d} ; \mathrm{Asp}=0.60 \mathrm{~mol} / \mathrm{d} ; \mathrm{Glu}=5.94 \mathrm{~mol} / \mathrm{d} ; \mathrm{Gly}=1.22$ $\mathrm{mol} / \mathrm{d}$; Ser $=2.45 \mathrm{~mol} / \mathrm{d})$.

${ }^{3}$ Probability corresponding to the null hypothesis with the 3 contrasts. Contrast infusions: Ctrl versus (Glc and C3 and NEAAm); contrast Glc and $\mathrm{C} 3$ versus NEAAm; contrast Glc versus C3.

${ }^{4}$ Branched essential AA $(\mathrm{EAA})=\mathrm{Ile}+\mathrm{Leu}+$ Val.

${ }^{5}$ Group $1=$ His + Met + Phe + Tyr $(+$ Trp not analyzed $)$; group $2=$ Ile + Leu + Val + Lys + Thr; and group $3=$ Ala + Asp + Asn + Cys $+\mathrm{Glu}+\mathrm{Gln}+\mathrm{Gly}+$ Pro + Ser + Arg.

The sum (Table 10) of plasma concentrations of essential AA (EAA) decreased with the infusions regardless of the type of nutrients infused, and this result is attributable to individual variation in most EAA except Thr and Met. There were, however, differences in the behavior of EAA. Concentrations of group 1 AA (sum of His, Met, Phe, and Tyr) decreased $(P=0.02)$ with all infused nutrients, but they decreased to a greater extent $(P<0.01)$ with NEAAm than with Glc and C3 and did not differ between Glc and C3. In contrast, group 2 of EAA (sum of Ile, Leu, Val, Lys, and Thr) was only decreased by infusions. The sum of branched chain AA (BCAA; Ile, Leu, and Val) also decreased $(P$ $<0.01)$ with the infused nutrients but were higher $(P<$
0.01) in NEAAm compared with Glc and C3 and were also higher $(P=0.05)$ in $\mathrm{C} 3$ than in Glc. For NEAA other than those infused, plasma concentrations of Pro, Tau, Orn, and Cit increased $(P<0.06)$ with NEAAm compared with Glc and C3, whereas concentrations of Gln tended to decrease $(P=0.08)$ with NEAAm. The plasma concentration of Arg was reduced $(P<0.01)$ with the infusions regardless of the type of nutrients infused.

\section{DISCUSSION}

The aim of this experiment, was to determine the effect of the type of nutrients (Glc, C3, and NEAAm), 
infused as iso-DE supplements to the diet, on $\mathrm{Ra}$ of glucose and milk lactose yield. As expected, infusions of C3 increased the percentage of propionic acid in the rumen by $14.2 \%$ and decreased the percentage of ruminal acetic acid by $11.3 \%$, whereas Glc infusions did not affect the percentages of ruminal VFA. The infusions of NEAAm greatly increased the plasma concentration of infused NEAA (from 3- to 29.5-fold), suggesting an increase in whole-body availability and several changes in AA metabolism, as it was observed for ammonia in the rumen and urea in the plasma. A large amount of NEAAm ( $+83.3 \%$ of PDI supply) had to be infused to provide iso-DE infusions, whereas infusions of Glc and C3 caused variations in digestive end products that could be encountered in dietary treatments (Lemosquet et al., 2004a). The comparison among the nutrients did not reflect the sole effect of each nutrient infused because DMI decreased slightly with the infusions; however, total DE supply (diet plus infusion) tended to increase with infusions and did not differ among the infusions.

\section{Increase in Ra with DE Supply Depends on the Type of Nutrients}

This increase in total DE supply (diet plus infusion) with the infusions of nutrients led to an increase in Ra. Expressed per Mcal of total DE supplies, the Ra obtained for the Ctrl treatment was similar $(0.23 \mathrm{mmol} /$ Mcal of DE, Table 6) to that previously reported in a review of dietary treatments (Wieghart et al., 1986). However, the type of nutrients had an effect on the Ra response, and infusions of Glc led to the highest Ra $(+745 \mathrm{mmol} / \mathrm{h})$ and to a significantly higher ratio of Ra to total DE supply $(0.324 \mathrm{~mol} /$ Mcal of total DE). The increase in Ra corresponded to $0.76,0.33$, and 0.32 of maximal glucose equivalent for Glc, C3, and NEAAm infusions, respectively (Table 2). This order was in accordance with reports in the literature comparing C3 with Glc (Seal and Parker, 1994; Lemosquet et al., 2004a). Infusions of glucogenic nutrients led to a higher increase in Ra compared with a single increment in DE. Increasing DE intake through diet also led to an increase in nongluconeogenic end products of digestion such as acetate or butyrate.

The increment in glucose Ra relative to Glc infusions (0.76) was slightly higher but fell within the same range as those obtained in previous experiments $(0.54$ and 0.60; Rigout et al., 2002; Lemosquet et al., 2004a) with similar doses of duodenally infused Glc. However, in these previous experiments, Glc treatments (diet plus infusion) were compared with isocaloric treatments, with the substitution of energy probably leading to a decrease in the availability of other glucose precursors.
A ratio lower than the unity could be explained by glucose utilization by the small intestine during absorption or by a decreased endogenous glucose production (Lemosquet et al., 2004a; Reynolds, 2006).

The increment in Ra obtained with C3 infusion only represented 0.33 of the maximal increment that could obtained if all infused C3 were used in gluconeogenesis (Table 2). This is in a range similar to the efficiency (0.4 of C3 carbons infused) observed in steers by Veenhuizen et al. (1988), despite a small reduction in DMI in the current study which could have limited the Ra increase. In ruminants, this ratio varies between 0.1 and 0.76 (Lemosquet et al., 2004a), and in dairy cows, when C3 was infused in isoenergetic substitution for a VFA mixture, this ratio was about 0.28 (Lemosquet et al., 2004a). The extra supply of C3, however, did not always increase hepatic glucose release or Ra (see review by Kristensen, 2005). One explanation for this is that increased portal C3 supply will be lower than rumen C3 supply, however portal C3 recovery of rumen irreversible loss varied ( 0.51 to 0.95 ) between experiment (Seal and Parker, 1994; Kristensen, 2005). At the liver, C3 can also substitute for other glucose precursors, which limits the increase in total gluconeogenesis (Seal and Parker, 1994). Another explanation could relate to increased C3 oxidation with a higher supply (Veenhuizen et al., 1988).

The increment in Ra obtained with NEAAm represented about 0.32 of the increase that could be expected if all of the infused AA were used in gluconeogenesis (Table 2) calculated with the Van Milgen model (2002). However, like C3 infusion, NEAAm reduced DMI, therefore decreasing gluconeogenesis resulting from dietary intake. The increase in Ra observed in response to NEAAm infusion was lower than the increment usually obtained with casein infusions. When expressed in mol of $\mathrm{C}$ in glucose per mol of infused $\mathrm{C}$, the increment in Ra corresponded of 0.23 (Table 2) of carbons infused as NEAAm (Table 2) and ranged from 0.14 to 0.89 of carbons infused as casein, with most values falling between 0.31 and 0.42 (Clark et al., 1977; König et al., 1984). Infusions of the most oxidized AA in the NEAAm mixture (Black et al., 1990) did not induce a higher Ra response than casein, which is a mixture of EAA and NEAA; however, from a biochemical standpoint, all AA are glucogenic except Leu and Lys (Wolff et al., 1972). The plasma concentrations of Asp, Glu, Ala, and Gly increased between 2.3- and 4.6-fold with NEAAm infusions relative to Glc and C3 infusions, whereas the plasma concentration of Ser increased 16.5fold compared with Glc and C3, pointing to significant differences in the utilization of these AA in particular to the different intestinal metabolism of NEAA infused, leading to a different NEAA profile in the portal vein 
(Doepel et al., 2007 ; Hanigan et al., 2004). In sheep, Ala and Glu accounted for 5.5 and $3.4 \%$ of Glc turnover, whereas Gly, Ser, and Asp accounted for less than 1\% (Wolff et al., 1972), which suggests that NEAAm was probably not the most efficient AA mixture for increasing Ra.

The NEAAm infusion increased plasma lactate and glucagon concentrations. The increment in lactate concentration probably resulted from extra lactate synthesis associated with Ala supplied in NEAAm. The glucagon concentration usually increases in response to AA infusion (Weekes et al., 2006) in ruminants, a trend that has been linked to increased hepatic uptake of AA and both stimulated glycogenolysis and gluconeogenesis (Brockman and Laarveld, 1986; Hippen et al., 1999) and hepatic oxidation of propionic acid (Gill et al., 1985). The increment observed in this study is quite high compared with the increments observed with AA mixtures (Weekes et al., 2006).

The rather low $\mathrm{Ra}$ values obtained with $\mathrm{C} 3$ and NEAAm could also be explained by the fact that gluconeogenesis efficiency could be driven by mammary demand of glucose. In the present experiment lactose yield was not increased which could have limit the Ra increase. Increasing glucose demand through the administration of phlorizin has been shown to increase Ra without an additional supply of precursor (Veenhuizen et al., 1988; Amaral-Phillips et al., 1993). In that scope, casein infusions increased milk yield (Clark et al., 1977) and increased Ra (Clark et al., 1977) more than NEAAm on the basis of carbon ratio (as discussed before).

\section{No Direct Link Between Ra and Yields of Milk and Lactose}

In the present experiment, Glc and C3 infusions increased glucose Ra but barely increased milk and lactose yields. Moreover, lactose yield with NEAAm infusion was lower than with the Ctrl treatment. Therefore, glucose availability appears not to have been a factor driving milk yield. This was observed even though a grass silage-based diet was fed to limit the supply of intestinal starch, so that the study was conducted under conditions in which glucose availability could be the main limiting factor, as reported in previous studies (Hurtaud et al., 2000; Rigout et al., 2002, 2003).

Similar infusions of C3 were already reported to barely increase milk yield (Raggio et al., 2006b). However, the absence of a significant increase in milk yield associated with Glc infusions in the present experiment seems surprising in light of the findings presented in the review by Rigout et al. (2003). One difference in this study compared with earlier investigations is that
Glc was infused in large amounts and used to supplement diet $(+12 \%$ of DMI), thereby increasing total energy supply $\left(+3\right.$ Mcal of $\left.\mathrm{NE}_{\mathrm{L}}\right)$ and decreasing the protein-to-energy-supply ratio. This stands in contrast with previous studies, in which proportional increases in lactose yield and Ra were observed (Rigout et al., 2002 ) in response to Glc infusions (0 to $5.3 \mathrm{~mol} / \mathrm{d}$ ). Because in the present experiment Glc was infused in supplement to the diet, an increase in total energy supply might have shifted glucose partitioning toward tissues other than the mammary gland, even though only plasma concentrations of IGF-1 increased, but not plasma insulin. However, an increase of muscle and adipose tissues sensitivity to insulin could not be excluded with Glc treatments (Lemosquet et al., 2002). In other studies, however, glucose and casein infusions that were provided to supplement diet increased or tended to increase glucose Ra, but only casein infusions increased milk yield (Clark et al., 1977; Ranawana and Kellaway, 1977). In addition, the inefficiency of NEAA in increasing milk yield has been reported (Kim et al., 2000) but EAA fraction of casein increased milk yield (Kim et al., 2000). All of these observations suggest that even in a grass silage-based diet, whole body glucose availability is not always the limiting factor for lactose synthesis, which could depend on the equilibrium between EAA supply and whole-body glucose availability.

\section{Ratio of Lactose Production to Ra Decreased with Increased Ra}

As in previous investigations (Rigout et al., 2002; Lemosquet et al., 2004a), as Ra increased, the ratio of lactose yield to Ra decreased. Glucose treatments exhibited the lowest ratios of lactose yield to $\mathrm{Ra}$ in the present experiment as well as in Lemosquet et al. (2004a). The decrease in glucose utilization for lactose synthesis may occur at several levels. First, glucose partitioning could change, favoring glucose utilization in tissues other than the mammary gland through increased glucose availability, including turnover of the glycogen pool. Second, part of the change in glucose utilization can also occur within the mammary gland. Important adjustments probably occurred in mammary gland metabolism because glucose levels in milk did not simply follow the trend in Ra or lactose. Mammary glucose uptake exceeds the requirements for lactose synthesis, and the excess glucose could increase and be used in metabolic pathways other than lactose synthesis when glucose availability is high. In the present experiment, these questions remain unanswered because mammary uptake of nutrients was not measured. The different modifications observed in milk composition and in plasma metabolites in the comparision of Glc 
and C3 with NEAAm suggest that both mechanisms were probably involved.

\section{Other Effects of Infusions on Milk Composition and Links to Metabolism}

Several of the parameters measured suggest that both mammary metabolism (increase in fatty acid elongation) and extra mammary metabolism (decrease in $\mathrm{C}_{18}$ fatty acid in milk and in BCAA concentration) were modified by Glc infusions and, to a lesser extent, by C3 infusions as previously observed (Rigout et al., 2002, 2003).

At the whole body level, the large dose of infused NEAAm probably greatly increased ureagenesis because the plasma urea concentration increased by $70 \%$. At the mammary gland level, the reduction of protein yield with NEAAm could be explained by a decrease of mammary uptake of AA from group 1 (Raggio et al., 2006a) because plasma concentration of AA in group 1 was decreased. Milk fat yield, the $\mathrm{C}_{18}$ yield, and plasma NEFA were higher in NEAAm compared with Glc and C3, and held steady at a level similar to the Ctrl. All of these responses suggesting fat precursor mobilization are in accordance with the negative net energy balance observed in NEAAm and Ctrl. However, the milk fat yield increased with NEAAm, mainly because the $\mathrm{C}_{16}$ fatty acid yield increased. It remains difficult to interpret this change of metabolism because $\mathrm{C}_{16}$ fatty acids are partly synthesized within the mammary gland and partly taken up directly from the blood supply.

\section{CONCLUSIONS}

Whole-body glucose Ra increased with increased digestible energy supply, but the magnitude of the increase depended not only on the DE infused but also on the type of nutrients infused in the digestive tract. Glucose had a greater effect in terms of increasing Ra compared with $\mathrm{C} 3$ and NEAAm. In the present experiment, with cows fed a grass silage-based diet providing only a little intestinal starch and a nonlimiting protein supply, milk and lactose yields were not affected by treatments, indicating that lactose synthesis was not only driven by an increase in Ra. The decrease in the ratio of lactose yield to Ra with increasing Ra suggests that glucose utilization shifted away from lactose synthesis toward other utilizations within the mammary gland and in other tissues.

\section{ACKNOWLEDGMENTS}

The authors are grateful to P. Lamberton and his team members, A. Cozien and D. Chevrel (INRA, UMR1080,
Dairy Production, Domaine de Mejusseaume, F-35650 Le Rheu, France),for their helpful assistance including the care, and feeding of cows; to J. N. Thibault (UMR1079 SENAH, INRA, Saint-Gilles, France) for the $\left[6,6-{ }^{2} \mathrm{H}_{2}\right]$ glucose enrichment analyses; to I. Jicquel, S. Marion, N. Huchet, J. Portanguan, M. Texier, M Vérité, and S. Wiard for technical assistance in UMR PL; to C. Morel and Y. Zbinden (Div. of Nutritional and Physiology, University of Berne, Switzerland) for the analyses of growth hormone and IGF-1. AgriResearch Canada translation services revised the English.

\section{REFERENCES}

Amaral-Phillips, D. M., A. D. McGilliard, G. L. Lindberg, J. J. Veenhuizen, and J. W. Young. 1993. Effects of decreased availability of glucose for dairy cows. J. Dairy Sci. 76:752-761.

Bermingham, E. N., P. Nozière, J. Vernet, H. Lapierre, S. Léger, D. Sauvant, and I. Ortigues-Marty. 2008. The relationships between intake and net portal fluxes of energy metabolites in ruminants: A meta-analysis. Anim. Feed Sci. Technol. 143:27-58.

Black, A. L., R. S. Anand, M. L. Bruss, C. A. Brown, and J. A. Nakagiri. 1990. Partitioning of amino acids in lactating cows: Oxidation to carbon dioxide. J. Nutr. 120:700-710.

Brockman, R. P., and B. Laarveld. 1986. Hormonal regulation of metabolism in ruminants; A review. Livest. Prod. Sci. 14:313334.

Clark, J. H., H. R. Spires, R. G. Derrig, and M. R. Bennink. 1977. Milk production, nitrogen utilization and glucose synthesis in lactating cows infused postruminally with sodium caseinate and glucose. J. Nutr. 107:631-644.

Danfaer, A. 1994. Nutrient metabolism and utilization in the liver. Livest. Prod. Sci. 34:115-127.

Doepel, L., G. E. Lobley, J. F. Bernier, P. Dubreuil, and H. Lapierre. 2007. Effect of glutamine supplmentation on splanchnic metabolism in lactating dairy cows. J. Dairy Sci. 90:4325-4333.

Gill, W., G. E. Mitchell, J. A. Boling, R. E. Tucker, G. T. Schelling, and R. M. DeGregorio. 1985. Glucagon influence on gluconeogenesis and oxidation of propionic acid and threonine by perfused ovine liver. J. Dairy Sci. 68:2886-2894.

Hanigan, M. D., C. K. Reynolds, D. J. Humphries, B. Lupoli, and J. D. Sutton. 2004. A model of net amino acid absorption and utilization by the portal-drained viscera of the lactating cow. J. Dairy Sci. 87:4247-4268.

Hippen, A. R., P. She, J. W. Young, D. C. Beitz, G. L. Lindberg, L. F. Richardson, and R. W. Tucker. 1999. Metabolic responses of dairy cows and heifers to various intravenous dosages of glucagon. J. Dairy Sci. 82:1128-1138.

Hurtaud, C., S. Lemosquet, and H. Rulquin. 2000. Effect of graded duodenal infusions of glucose on yield and composition of milk from dairy cows. 2. Diets based on grass silage. J. Dairy Sci. 83:2952-2962.

INRA. 1989. Ruminant Nutrition: Recommended Allowances and Feed Tables. R. Jarrige, ed. John Libbey Eurotext, London, UK.

Kim, C. H., J. J. Choung, and D. G. Chamberlain. 2000. The effects of intravenous administration of amino acid and glucose on the milk production of dairy cows consuming diets based on grass silage. Grass Forage Sci. 55:173-180.

König, B. A., J. D. Oldham, and D. S. Parker. 1984. The effect of abomasal infusion of casein on acetate, palmitate and glucose kinetics during early lactation. Br. J. Nutr. 52:319-328.

Kristensen, N. B. 2005. Splanchnic metabolism of volatile fatty acids in the dairy cow. Anim. Sci. 80:3-10.

Lemosquet, S., E. Debras, M. Balage, J. F. Hocquette, H. Rulquin, and J. Grizard. 2002. Hyperglycemia enhanced the insulin stimulated glucose disposal in lactating goats. Am. J. Physiol. 282:R464R474. 
Lemosquet, S., N. Rideau, H. Rulquin, P. Faverdin, J. Simon, and R. Vérité. 1997. Effect of a duodenal glucose infusion on the relationship between plasma concentrations of glucose and insulin in dairy cows. J. Dairy Sci. 80:2854-2865.

Lemosquet, S., S. Rigout, A. Bach, H. Rulquin, and J. W. Blum. 2004a. Glucose metabolism in lactating cows in response to isoenergetic infusions of propionic acid or duodenal glucose. J. Dairy Sci. 87:1767-1777.

Lemosquet, S., J. N. Thibault, A. Thomas, E. Debras, and C. Hurtaud 2004 b. Validation of the measurement of glucose appearance rate with $\left[6,6-{ }^{2} \mathrm{H}_{2}\right]$ glucose in lactating dairy cows. Reprod. Nutr. Dev. $44: 17-27$.

Negrao, J. A., and P. G. Marnet. 2006. Milk yield, residual milk, ocytocin and cortisol release during machine milking in Gir, Gir $\times$ Holstein and Holstein cows. Reprod. Nutr. Dev. 46:77-85.

Offner, A., A. Bach, and D. Sauvant. 2003. Quantitative review of in situ starch degradation in the rumen. Anim. Feed Sci. Technol. 106:81-93.

Offner, A., and D. Sauvant. 2004. Prediction of in vivo starch digestion in cattle from in situ data. Anim. Feed Sci. Technol. 111:41-56.

Raggio, G., S. Lemosquet, G. E. Lobley, H. Rulquin, and H. Lapierre. 2006a. Effect of casein and propionate supply on mammary protein metabolism in lactating dairy cows. J. Dairy Sci. 89:4340-4351.

Raggio, G., G. E. Lobley, S. Lemosquet, H. Rulquin, and H. Lapierre. 2006b. Effect of casein and propionate supply on whole body protein metabolism in lactating dairy cows. Can. J. Anim. Sci. 86:81-89.

Ranawana, S. S. E., and R. C. Kellaway. 1977. Responses to postruminal infusions of glucose and casein in lactating goats. Br. J. Nutr. $37: 395-402$

Reynolds, C. K. 2006. Production and metabolic effects of site of starch digestion in dairy cattle. Anim. Feed Sci. Technol. 130:78-94.
Rigout, S., C. Hurtaud, S. Lemosquet, A. Bach, and H. Rulquin. 2003. Lactational effect of propionic acid and duodenal glucose in cows. J. Dairy Sci. 86:243-253.

Rigout, S., S. Lemosquet, J. E. Van Eys, J. W. Blum, and H. Rulquin. 2002. Duodenal glucose increases glucose fluxes and lactose synthesis in grass silage-fed dairy cows. J. Dairy Sci. 85:595606 .

SAS Institute. 2004. SAS/STAT ${ }^{\circledR}$ SAS User's Guide: Statistics. Version 9.1. SAS Inst. Inc., Cary, NC.

Sauvant, D., J. M. Perez, and G. Tran. 2004. Tables de composition et de valeur nutritive des matières premières destinées aux animaux d'élevage. INRA editions, Paris, France.

Seal, C. J., and D. S. Parker. 1994. Effect of intraruminal propionic acid infusion on metabolism of mesenteric- and portal-drained viscera in growing steers fed a forage diet: I. volatile fatty acids, glucose and lactate. J. Anim. Sci. 72:1325-1334.

Van Milgen, J. 2002. Modeling biochemical aspects of energy metabolism in mammals. J. Nutr. 132:3195-3202.

Veenhuizen, J. J., R. W. Russell, and J. W. Young. 1988. Kinetics of metabolism of glucose, propionate and $\mathrm{CO}_{2}$ in steers as affected by injecting phlorizin and feeding propionate. J. Nutr. 118:13661375.

Weekes, T. L., P. H. Luimes, and J. P. Cant. 2006. Responses to amino acid imbalances and defiencies in lactating dairy cows. J. Dairy Sci. 89:2177-2187.

Wieghart, M., R. Slepetis, J. M. Elliot, and D. F. Smith. 1986. Glucose absorption and hepatic gluconeogenesis in dairy cows fed diets varying in forage content. J. Nutr. 116:839-850.

Wolff, J. E., E. N. Bergman, and H. H. Williams. 1972. Net metabolism of plasma amino acids by liver and portal-drained viscera of fed sheep. Am. J. Physiol. 223:438-446. 